\title{
BAIXA QUALIDADE AMBIENTAL DE PRAÇAS BASEADA EM ÍNDICES DE COBERTURA VEGETAL EM CIDADE DE PEQUENO PORTE
}

\section{LOW ENVIRONMENTAL QUALITY OF SQUARES BASED ON VEGETATION COVERAGE INDICES IN A SMALL TOWN}

\section{BAJA CALIDAD AMBIENTAL DE PLAZAS BASADA EN ÍNDICES DE COBERTURA VEGETAL EN CIUDADES PEQUEÑAS}

\author{
Felipe Teixeira Dias ${ }^{1}$ https://orcid.org/0000-0001-7985-812X \\ Carlos Magno Santos Clemente ${ }^{2}$ https://orcid.org/0000-0002-1087-5228 \\ Deborah Marques Pereira ${ }^{3}$ https://orcid.org/0000-0002-4722-6686 \\ Jardel Gybson Soares Costa ${ }^{4}$ https://orcid.org/0000-0002-6225-7747 \\ Nário Jardel Martins de Oliveira ${ }^{5}$ https://orcid.org/0000-0002-1215-6569
}

\footnotetext{
${ }^{1}$ Graduando em Direito pelo Centro Universitário FG - UniFG. Pesquisador do Observatório UniFG do Semiárido Nordestino/ Centro Universitário FG - UniFG, Guanambi, BA. E-mail: felipeteixeiradias@ gmail.com

${ }^{2}$ Doutorando Geoprocessamento (PUC-MG); Mestre em Ciências biológicas e geografia (UNIMONTES/MG). Pesquisador e Coordenador do Observatório UniFG do Semiárido Nordestino/Centro Universitário FG - UniFG, Guanambi, BA. E-mail: carlosmagno.clemente@gmail.com

3 Doutoranda em Direito pela Universidad Buenos Aires (UBA-AR); Mestre em Desenvolvimento Social (UNIMONTES). Coordenadora de Pesquisa do Centro Universitário FG - UniFG. Coordenadora do Observatório UniFG do Semiárido Nordestino. E-mail: deborah.marques@ professor.centrouniversitariounifg.edu.br

${ }^{4}$ Graduado em Engenharia Civil pelo Centro Universitário FG - UniFG. Pesquisador egresso do Observatório UniFG do Semiárido Nordestino/ Centro Universitário FG - UniFG, Guanambi, BA. E-mail: jgsoaresc@ gmail.com
}

\section{RESUMO}

A presente pesquisa emerge de uma construção teórico-metodológica embasada na tríade: Cidade, Meio Ambiente e Qualidade de Vida, elementos estes que devem coexistir na malha urbana, observando às funcionalidades socioambientais da cidade, objetivo linear da Política Urbana Brasileira. Nesse contexto, verificou-se à necessidade de traçar métodos e diretrizes de estudos multidisciplinares, considerando às nuances espaciais, ambientais e urbanísticas. Desse modo, no presente estudo buscou-se dialogar com os conceitos de cobertura vegetal e áreas verdes. Assim, o método empregado baseia-se na integração de dados teóricos e práticos, definindo: a) áreas verdes e vegetação; b) Meio Ambiente; e, c) praças e áreas de lazer. Para compreender a essa tríade, tornou-se necessário o estudo do espaço geográfico definindo uma área de estudo como sendo a cidade de Guanambi (Bahia), e a projeção espacial das áreas consideradas como praças. Para tanto, utilizou-se uma abordagem quali-quantiva, e o método de estudo de caso. Valendo-se ainda de geotecnologias. Compreendeu-se que o Índice de Área Verde Total (IAVT) se encontra abaixo do índice recomendado pelos órgãos internacionais, isto nas áreas das praças de Guanambi.

Palavras-chave: Espaço de Lazer. Espaços Urbanos Livres. Áreas de Recreação. 
Baixa qualidade ambiental de praças baseada em índices de cobertura vegetal em cidade de pequeno porte

Felipe T. Dias; Carlos Clemente; Deborah M. Pereira; Jardel G. S. Costa; Nário J. M. de Oliveira

\begin{abstract}
The present research emerges from a theoretical and methodological construction based on the triad: City, Environment and Quality of Life, elements that must coexist in the urban fabric, observing the socio-environmental functionalities of the city, a linear objective of the Brazilian Urban Policy. In this context, there was a need to outline methods and guidelines for multidisciplinary studies, considering spatial, environmental and urban nuances. Thus, in this study, we sought to dialogue with the concepts of vegetation cover and green areas. Thus, the method employed is based on the integration of theoretical and practical data, defining: a) green areas and vegetation; b) Environment; and, c) squares and leisure areas. To understand this triad, it became necessary to study the geographic space, defining a study area as the city of Guanambi (Bahia), and the spatial projection of the areas considered as squares. For this, a qualitative and quantitative approach was used, as well as the case study method. Also using geotechnologies. It was understood that the Total Green Area Index (IAVT) is below the index recommended by international bodies, that is, in the areas of Guanambi squares.
\end{abstract}

Keywords: Leisure Space. Free Urban Spaces. Recreation Areas

\title{
RESUMEN
}

La presente investigación surge de una construcción teórica y metodológica basada en la tríada: Ciudad, Medio Ambiente y Calidad de Vida, elementos que deben convivir en el tejido urbano, observando las funcionalidades socioambientales de la ciudad, un objetivo lineal de la Política Urbana Brasileña. En este contexto, era necesario delinear métodos y lineamientos para estudios multidisciplinarios, considerando matices espaciales, ambientales y urbanos. Así, en este estudio se buscó dialogar con los conceptos de cobertura vegetal y áreas verdes. Así, el método empleado se basa en la integración de datos teóricos y prácticos, definiendo: a) áreas verdes y vegetación; b) Medio ambiente; y, c) plazas y áreas de esparcimiento. Para comprender esta tríada, se hizo necesario estudiar el espacio geográfico, definiendo un área de estudio como la ciudad de Guanambi (Bahía), y la proyección espacial de las áreas consideradas como cuadrados. Para eso, se utilizó un enfoque de calidad y cantidad para el estudio de casos. Y tambien el uso de geotecnologías. Se entendió que el Índice Total de Áreas Verdes (IAVT) está por debajo del índice recomendado por organismos internacionales, es decir, en las áreas de las plazas de Guanambi.

Palabras clave: Espacio de ocio. Espacios Urbanos Libres. Áreas de recreación.

\section{INTRODUÇÃO}

A cobertura vegetal é um conceito amplo, sendo definido como a projeção do verde que pode ser identificada a partir de fotografias aéreas. Para tanto, leva-se em consideração toda a cobertura vegetal existente nos loteamentos edificados ou não, espaços livres e nos espaços de integração das cidades (AMORIM; LIMA, 2006).

De acordo Amorim e Lima (2006), dentro do conceito de cobertura vegetal encontram-se as áreas verdes, que podem ser consideradas como um tipo especial de espaços 
Baixa qualidade ambiental de praças baseada em índices de cobertura vegetal em cidade de pequeno porte

Felipe T. Dias; Carlos Clemente; Deborah M. Pereira; Jardel G. S. Costa; Nário J. M. de Oliveira

livres, em que, sua principal característica é a vegetação. Essa cobertura vegetal deve possuir como meta a satisfação de três objetivos primordiais: ecológico-ambiental, estético e de lazer (AMORIM; LIMA, 2006).

Em função disso, existem nos espaços intraurbanos os ambientes livres e de lazer, ou seja, as praças, que se caracterizam como espaços livres direcionados a atividades de recreação e interação entre os usuários, atuando como elemento amenizador e organizador da circulação pública, contendo em geral alguma cobertura vegetal, canteiros e bancos (MENDONÇA, 2007).

Por outro condão, em uma conceituação ampla das praças, podem ser definidas como qualquer espaço público livre de edificações e que esteja destinado a propiciar o convívio social entre os citadinos (VIERO; BARBOSA FILHO, 2009). Coaduna-se com essa ideia às reflexões de Lefebvre (2016), que destaca o uso da cidade perpassa por dinâmicas que ensejam a dar um novo significado aos espaços da cidade. Dentre os diversos espaços que compõe a cidade, tem-se como um espaço comum entre os citadinos as áreas de lazer, as quais promovem a socialização das camadas sociais da cidade (LEFEBVRE, 2016).

Nesse prisma, é previsto pelo artigo $2^{\circ}$ do Estatuto da Cidade que dentre as principais diretrizes da Política Urbana, está o objetivo de garantir além do direito a cidades sustentáveis, o lazer para as presentes e futuras gerações. Além disso, há o art. 225 da Constituição Federal de 1988 que determina o direito ao meio ambiente ecologicamente equilibrado, "bem de uso comum do povo e essencial à sadia qualidade de vida, impondo-se ao Poder Público e à coletividade o dever de defendê-lo e preservá-lo para as presentes e futuras gerações" (BRASIL, 1988).

As geotecnologias se caracterizam como instrumentos que auxiliaram na compreensão acerca dos fenômenos do espaço geográfico, como exemplos os urbanos e ambientais. Esse conjunto de instrumentos geotecnológicos oferecem aos gestores e pesquisadores artifícios para planejamento e análise direcionada para um uso racional do espaço da cidade e uma melhor elaboração e contribuição para as políticas públicas que objetivem elevar o nível de qualidade de vida dos citadinos (LEITE, 2011).

Nesse contexto, a presente pesquisa teve como objetivo realizar um estudo intraurbano da cobertura vegetal das praças de Guanambi-BA, relacionando as diretrizes da política urbana e meio ambiente. Para tanto, utilizou-se das geotecnologias como ferramenta de subsídio no cálculo e obtenção dos Índice de Cobertura Vegetal e Índice de Área Verde Total (HARDER; RIBEIRO; TAVARES, 2006). 
Baixa qualidade ambiental de praças baseada em índices de cobertura vegetal em cidade de pequeno porte

Felipe T. Dias; Carlos Clemente; Deborah M. Pereira; Jardel G. S. Costa; Nário J. M. de Oliveira

Logo, justifica-se a pertinência em comento, pois a partir deste estudo é possível contribuir para o conhecimento crítico, social e científico sobre a cobertura vegetal na infraestrutura das praças de Guanambi. E um conjunto de informações científicas relevantes para a atuação pública. Principalmente em obediência a Constituição Federal (art. 225), juntamente com a coletividade como agentes promotores do desenvolvimento urbanosustentável e de sua defesa e preservação para as presentes e futuras gerações.

\section{PROCEDIMENTOS METODOLÓGICOS}

A metodologia da pesquisa traçada nesta investigação constitui-se a partir de um estudo de caso, e segue uma abordagem quali-quantitativa sobre o entendimento acerca do espaço intraurbano e seus fenômenos. Buscou-se analisar o quantitativo de vegetação das praças existentes na cidade de Guanambi/BA e em seguida, calcular o Índice de Cobertura Vegetal (ICV) e o Índice de Área Verde Total (IAVT), esta técnica foi utilizada por Harder, Ribeiro e Tavares, (2006) e Clemente et al., (2019).

\section{Área de estudo}

Para realização da pesquisa, delimitou-se o espaço intraurbano da cidade de Guanambi, no estado da Bahia (BA), como área de estudo, localizado entre as coordenadas geográficas $42^{\circ} 44^{\prime} 45^{\prime \prime}$ a $42^{\circ} 48^{\prime} 41^{\prime}$ 'O e $14^{\circ} 11^{\prime} 40^{\prime \prime}$ a $14^{\circ} 14^{\prime} 57^{\prime} \mathrm{S}$, situada no semiárido baiano (Mapa 1) (IBGE, 2011).

De acordo com o censo do IBGE (2010), o município apresentou um total de 78.833 habitantes, destes 62.565 (79,3\%) são moradores da área urbana e 16.268 (20,7\%) residem na zona rural, sendo que 58.111 pessoas $(73,7 \%)$ se localizam na sede municipal (cidade). A população estimada do ano de 2019 alcançou 84.481 moradores (IBGE, 2019). 
Baixa qualidade ambiental de praças baseada em índices de cobertura vegetal em cidade de pequeno porte

Felipe T. Dias; Carlos Clemente; Deborah M. Pereira; Jardel G. S. Costa; Nário J. M. de Oliveira

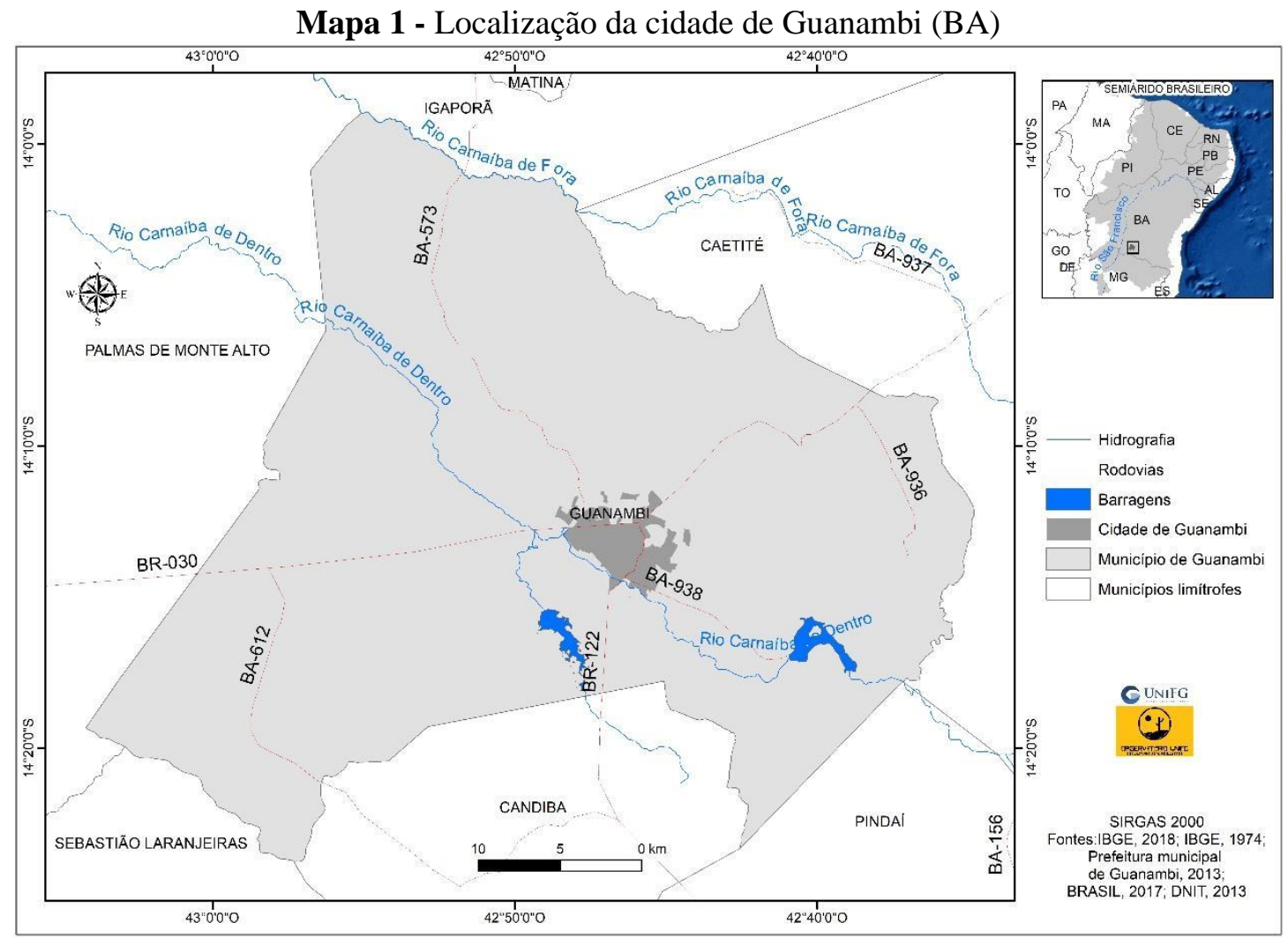

Fontes: Prefeitura Municipal de Guanambi, 2019

Org.: Autores, 2021

Na região de localização do município de Guanambi, a vegetação predominante é constituída pela caatinga e manchas de cerrado (CLEMENTE, et al., 2019). A caatinga é encontrada com maior predominância a partir de manchas de tamanhos variados, sendo bioma estritamente brasileiro. No entanto, em razão da intensa atividade humana por meio da agricultura e agropecuária, resta pouco da vegetação natural (OLIVEIRA JUNIOR; PEREIRA, 2016).

\section{MATERIAIS E MÉTODOS}

Para os procedimentos metodológicos seguiram-se 3 (três) etapas, o levantamento de dados teóricos e técnicos, os procedimentos técnicos para identificar e quantificar as praças e a análise dos dados (Figura 1). 
Baixa qualidade ambiental de praças baseada em índices de cobertura vegetal em cidade de pequeno porte

Felipe T. Dias; Carlos Clemente; Deborah M. Pereira; Jardel G. S. Costa; Nário J. M. de Oliveira

Figura 1: Etapas da pesquisa

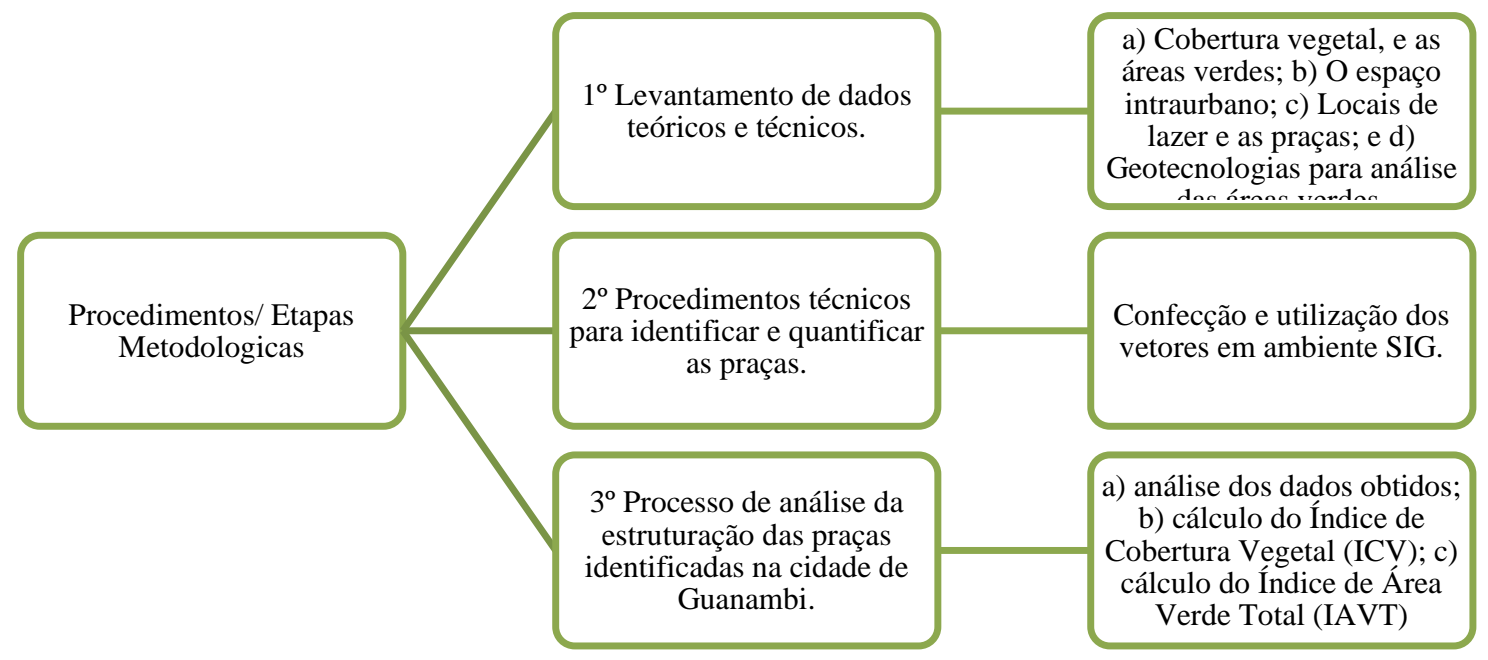

Primeiramente, realizou-se um levantamento bibliográfico sobre a cobertura vegetal no espaço intraurbano, bem como, as tecnologias para as análises do espaço geográfico, em específico, os seguintes aparatos teóricos: a) A cobertura vegetal, e as áreas verdes; b) O espaço intraurbano; c) Locais de lazer e as praças; e d) $\mathrm{O}$ uso das geotecnologias para análise das áreas verdes.

Em uma segunda etapa foram realizados procedimentos técnicos para identificar e quantificar as praças que estão situadas no espaço intraurbano de Guanambi no ano de 2018. Utilizou-se da base de dados cadastrais sobre as praças do ano de 2017, ofertada pela Prefeitura Municipal de Guanambi (GUANAMBI, 2017).

Foram verificadas as praças mapeadas pela prefeitura no ano de 2017, em do ambiente Computer Aided Design (CAD). Posteriormente realizou-se a conversão das extensões CAD para Sistema de Informação Gegráfica (SIG) a partir do aplicativo ArcMap do Software ArcGis. Os dados obtidos da prefeitura foram sobrepostos com a imagem de satélite Geoeye WorldView-3 (29/07/2018, 30 centímetros de resolução espacial do ano 2018) correspondente ao período seco em Guanambi, que permitiu o refinamento dos vetores das praças de Guanambi e sua atualização para o ano de 2018. Nessa etapa, para o refinamento e atualização das praças, foram utilizados os procedimentos de fotointerpretação, vetorização e constituição do banco de dados alfanumérico georreferenciados. Logo após, foram mapeadas (fotointerpretação e vetorização) as copas das estruturas arbórea-arbustiva contida no espaço das praças selecionadas. 
Baixa qualidade ambiental de praças baseada em índices de cobertura vegetal em cidade de pequeno porte

Felipe T. Dias; Carlos Clemente; Deborah M. Pereira; Jardel G. S. Costa; Nário J. M. de Oliveira

Para os índices relativos à cobertura vegetal, foi adotado o método proposto por Harder et al., (2006). Calculou-se o Índice de Área Verde Total (IAVT) das praças considerando a soma da área total das praças dividida pelo número de habitantes da área Urbana (58.111 citadinos censo IBGE, 2010), por meio da seguinte fórmula:

$$
I A V T=\sum \frac{\text { áreas totais das praças }}{\text { habitantes da área urbana }}
$$

Em seguida, para identificar o Índice de Cobertura Vegetal (ICV) das praças de Guanambi foi levado em consideração a soma da área das copas das árvores em relação ao quantitativo de habitantes urbanos (58.111 pessoas, censo IBGE, 2010), fórmula a seguir:

$$
I C V=\sum \frac{\text { área das copas }}{\text { habitantes da área urbana }}
$$

Os resultados obtidos foram comparados com os indicadores sugeridos pela Organização das Nações Unidas (ONU) e a Organização Mundial da Saúde (OMS) - de no mínimo $12 \mathrm{~m}^{2}$ de área verde por habitante para que se tenha alta qualidade ambiental, levando-se em conta a população e a cobertura vegetal disponível no espaço urbano - bem como, com os índices obtidos em outras cidades brasileiras por meio da literatura científica (BORGES et al, 2012). Todo o procedimento técnico para a fotointerpretação, vetorização, organização e representação da cobertura vegetal foi realizada no ArcGIS 10.2.2.

$\mathrm{Na}$ terceira etapa foi realizada o processo de resultados e discussão dos dados das praças identificadas na cidade de Guanambi.

\section{A COBERTURA VEGETAL NO ESPAÇO INTRAURBANO}

Preliminarmente, destaca-se o pensamento de Nucci (2008), que define o termo "cobertura vegetal" como manchas de vegetação visualizadas sem uso de instrumento óptico em foto aérea na escala 1:10.000. Essas manchas, não permitem uma perfeita visibilidade das copas das árvores cujos diâmetros sejam inferiores a 2m. Para Amorim e Lima (2006) a cobertura vegetal abarca toda a projeção do verde existente nos espaços livres, espaços construídos e espaços de integração.

Com os desafios e problemas gerados pelas cidades, as áreas verdes passaram a desempenhar um papel de higienização, recreação e manutenção da qualidade ambiental do espaço urbano (AMORIM; LIMA, 2006). A substituição das paisagens verdes pelas construções de concreto das cidades trouxe significativos impactos na qualidade do clima das 
Baixa qualidade ambiental de praças baseada em índices de cobertura vegetal em cidade de pequeno porte

Felipe T. Dias; Carlos Clemente; Deborah M. Pereira; Jardel G. S. Costa; Nário J. M. de Oliveira

cidades, e na drenagem das águas, por exemplo, corroborando para que as áreas urbanas se tornassem sinônimos de desequilíbrios ecossistêmicos, processos de erosão e degradação (AMORIM; LIMA, 2006).

Conforme preleciona Amorim e Lima (2006), as áreas verdes possuem e exercem múltiplas funções na cidade, além de contribuírem no equilíbrio do meio ambiente urbano, oferecem um colorido e plasticidade ao mesmo. Por outro lado, a falta de vegetação na malha urbana acarreta consequências negativas que afetam a estrutura da cidade e a vida da população. Tais como alterações significativas no clima, na temperatura média, enchentes nos períodos chuvosos, deslizamentos de terra e falta de áreas ecológicas para o lazer (AMORIM; LIMA, 2006).

Assim, a cobertura vegetal difere-se das áreas verdes, pois, essas são compreendidas como uma espécie de espaço livre tendo como principal característica a presença de vegetação e solo permeável em pelo menos 70\% de sua área (AMORIM; LIMA, 2006).

Por conseguinte, o conceito de áreas verdes também se dissocia das praças uma vez que estas são espaços livres destinados ao convívio social e recreação podendo conter ou não expressiva cobertura vegetal, mobiliário lúdico, solo permeável ou impermeável (MENDONÇA, 2007).

Noutra perspectiva, as praças podem ser definidas, de maneira ampla, como qualquer espaço público urbano, livre de edificações que propicie convivência e/ou recreação para os seus usuários (VIERO; BARBOSA FILHO, 2009). Nesse prisma tornam-se locais de socialização, de encontros, lazer e de convívio social (LEFEBVRE, 2016). Nesse sentido, vale redobrar a atenção voltada para os espaços de lazer, sendo em sua predominância às praças, estas que devem conter um nível de utilização e satisfação que possa viabilizar o cumprimento de sua função social.

Em função disso, Carvalho, Ribeiro e Rodrigues (2016) destacam que na contemporaneidade diversos problemas afrontam tanto à política urbana quanto ambiental, sendo em grande parte causadores de degradação ambiental, com aumento de poluição, do desmatamento e diminuição de áreas verdes nas cidades.

Tal problemática afronta diretamente às funções sociais lazer, de preservação ambiental e de convívio social em locais urbanos que primam em produzir espaços adequados a sua devida utilização e sociabilização (CARVALHO; RIBEIRO; RODRIGUES, 2016). 
Baixa qualidade ambiental de praças baseada em índices de cobertura vegetal em cidade de pequeno porte

Felipe T. Dias; Carlos Clemente; Deborah M. Pereira; Jardel G. S. Costa; Nário J. M. de Oliveira

\section{As geotecnologias e sua aplicabilidade aos estudos da cobertura vegetal}

Para adentrar propriamente aos conceitos das geotecnologias, é primordial destacar um percurso histórico de seu surgimento. Nesse contexto, com a finalidade de elaborar um inventário de recursos naturais, na década de 1960 surgiu no Canadá por meio de um programa governamental, um aparato tecnológico de análise e representação do espaço, o Sistema de Informação Geográfica (SIG) (CÂMARA; DAVIS, MONTEIRO, 2001).

Entre avanços tecnológicos, atualmente as geotecnologias se constituem como ferramentas de prática social (MATIAS, 2004). Uma vez que sua utilização se tornou acessível às mais diversas classes sociais, a fim de influenciar na compreensão do grande público acerca de como se vê o espaço geográfico (MATIAS, 2004).

Conforme Rosa (2005) as geotecnologias são um conjunto de técnicas objetivadas a identificar, coletar, processar, analisar, integrar e ofertar dados georreferenciados para a tomada de soluções. Portanto, são empregadas nos mais diversos usos e aplicações, como para: a gestão ambiental; o gerenciamento dos sistemas de transportes; a gestão da frota municipal; o ordenamento territorial; e o planejamento e gerenciamento dos recursos naturais; e entre outros (VALDIVINO; MATOS; OLIVEIRA, 2016).

Vale ainda destacar as principais técnicas presentes nas Geotecnologias tais como: o Sensoriamento Remoto; o Processamento Digital de Imagens (PDI) o Sistema de Informação Geográfica (SIG); o Sistema de Posicionamento Global; a Cartografia Digital; e a Topografia (ROSA, 2005). Destarte, tem-se como principais funções através das suas ferramentas: a construção de um banco de dados com informações sociais, econômicas e ambientais; a constituição de uma base cartográfica sobre a área de estudo; e a elaboração de mapas sobre a configuração territorial dos municípios e das características do seu meio físico (VALDIVINO; MATOS; OLIVEIRA, 2016).

O sensoriamento remoto enquanto uma técnica das Geotecnologias, consiste em obter dados sobre todo tipo de componente presente no espaço geográfico sem que haja o contato físico com este (ROSA, 2005). Destarte, os dados são obtidos por meio da reflexão e/ou emissão de radiação eletromagnética gerada pelo objeto analisado, que são produzidas por fontes naturais como o sol e a terra ou artificial como o radar (ROSA, 2005).

Vale ressaltar que, atualmente o estudo de imagens de sensoriamento remoto tem se tornado cada vez mais importante (FONSECA, 2008). Em função do seu grande destaque frente às acentuadas transformações socioespaciais e pela necessidade de se interpretar os diversos fenômenos que ocorrem sobre dado espaço (FONSECA, 2008). 
Baixa qualidade ambiental de praças baseada em índices de cobertura vegetal em cidade de pequeno porte

Felipe T. Dias; Carlos Clemente; Deborah M. Pereira; Jardel G. S. Costa; Nário J. M. de Oliveira

O SIG é entendido como uma técnica utilizada para coletar, armazenar, tratar, analisar, integrar e representar dados gráficos e não gráficos (ROSA, 2005). Em função do estudo do espaço acerca da cobertura vegetal das praças, faz-se necessário o uso de ferramentas capazes de realizar tal análise (ROSA, 2005). Para tanto, as Geotecnologias são recomendadas para este fim, uma vez que são utilizadas com a finalidade de elaborar produtos cartográficos para a representação dos dados espaciais obtidos (ROSA, 2005).

Diante disso, é válido destacar que as técnicas das Geotecnologias para o estudo da cobertura vegetal das praças são de grande relevância (VALDIVINO; MATOS; OLIVEIRA, 2016). Visto que essas têm como finalidade contribuir com a avaliação e representação do espaço geográfico e dos possíveis impactos na vida dos citadinos em função dos dados obtidos (VALDIVINO; MATOS; OLIVEIRA, 2016).

Desse modo, às geotecnologias aplicáveis ao estudo da cobertura vegetal, sobretudo no espaço intraurbano, serão tratadas no próximo tópico, buscando abordar e correlacionar o uso das geotecnologias para uma análise do espaço da cidade de Guanambi/BA.

\section{PRAÇAS URBANAS: ACEPÇÕES E CONCEPÇÕES}

O termo praça vem do latim platea, podendo ser descrita como qualquer espaço público urbano livre de edificações, propiciando o lazer, a socialização e a oportunidade de convivência entre seus usuários, logo, sua definição varia de acordo com cada cultura e população (VIERO; BARBOSA FILHO, 2009). Por conseguinte, tornam-se locais de socialização, de encontros, lazer e de convívio social (LEFEBVRE, 2016).

É necessário reconhecer que este espaço tem uma conexão com diversas partes da cidade, existindo a necessidade de planejamento e estruturação. Na perspectiva de Santos (1997, p. 39) “O espaço é formado por um conjunto indissociável, solidário e contraditório, de sistemas de objetos e sistemas de ações, não considerados isoladamente, mas como o quadro único no qual a história se dá”.

Sob este cenário, torna-se importante compreender o significado de praça sob o ponto de vista de alguns autores desde sua origem. Neste sentido, de acordo Rigotti (1956) as praças são locais onde a população se reúne para fins sociais, religiosos, políticos, comerciais, podendo utilizá-las para desenvolver atividades de entretenimento.

Nessa perspectiva, hodiernamente, a praça é o lugar apropriado para toda a comunidade, da permanência, dos acontecimentos, "de práticas sociais, de manifestações da vida urbana e comunitária" e, sendo assim, de funções estruturantes e arquiteturas significativas (LAMAS, 1993, p.26). 
Baixa qualidade ambiental de praças baseada em índices de cobertura vegetal em cidade de pequeno porte

Felipe T. Dias; Carlos Clemente; Deborah M. Pereira; Jardel G. S. Costa; Nário J. M. de Oliveira

Parte-se de uma análise, em que a praça traz uma definição pelos elementos construídos e por sua vegetação. Posto isso, os espaços que a constituem podem ser classificados de acordo com Macedo e Robba (2002) em praça Jardim, praça Seca, praça Azul e praça Amarela (Quadro 01).

Quadro 1 - Classificação descritiva das praças

\begin{tabular}{|c|c|c|c|}
\hline \multicolumn{4}{|c|}{ Classificação das Praças } \\
\hline Praça Jardim & Praça Seca & Praça Azul & Praça Amarela \\
\hline $\begin{array}{l}\text { A característica } \\
\text { principal da Praça } \\
\text { Jardim, é a presença } \\
\text { de espécies } \\
\text { vegetais/natureza. }\end{array}$ & $\begin{array}{l}\text { A característica } \\
\text { principal desse tipo } \\
\text { de praça é uma maior } \\
\text { circulação de } \\
\text { pedestres, tendo } \\
\text { como valor principal } \\
\text { sua arquitetura. }\end{array}$ & $\begin{array}{l}\text { A praça Azul se } \\
\text { destaca } \\
\text { quantidade de água. }\end{array}$ & $\begin{array}{l}\text { Amarela, que é } \\
\text { reconhecida pelas } \\
\text { praias. }\end{array}$ \\
\hline
\end{tabular}

Fonte: Macedo; Robba, 2002. Org.: Autores, 2020.

Nesse sentido, o primeiro tipo de praça caracteriza-se por ser composta por espécies vegetais e o contato direto com a natureza, possibilitando um ar puro e podendo ser fechadas ou abertas. A segunda, a praça Seca, é a que possui a maior circulação de pedestres, algumas delas não possui árvores ou até mesmo jardins, neste tipo de praça é valorizada a arquitetura. Todavia, a praça Azul se destaca pela imensa quantidade de água, diferentemente da praça Amarela, que é reconhecida pelas praias (MACEDO; ROBBA, 2002).

Em função disso, vale redobrar a atenção voltada para os espaços de lazer, sendo em sua predominância as praças, estas que devem conter um nível de utilização e satisfação que possa viabilizar o cumprimento de sua função social e ambiental. Nessa perspectiva, compreende-se que as praças enquanto locais de lazer, também promovem uma função com o equilíbrio natural através da constituição de áreas verdes nas praças existentes no espaço intraurbano. Contudo a discussão sobre as áreas verdes será tratada no próximo tópico de maneira mais específica.

\section{ANÁlise INTRAURBANA DA COBERTURA VEGETAL DAS PRAÇAS DE GUANAMBI}

As praças existentes no espaço intraurbano constituem um elemento urbanístico e ambiental que corroboram com as funções socioambientais das cidades. Tais funções são 
Baixa qualidade ambiental de praças baseada em índices de cobertura vegetal em cidade de pequeno porte

Felipe T. Dias; Carlos Clemente; Deborah M. Pereira; Jardel G. S. Costa; Nário J. M. de Oliveira

resguardadas de forma legal pela Constituição Federal de 1988, bem como pelo Estatuto da Cidade (Lei 10.257/2001) e outros regramentos que corroboram com essa dinâmica. Desse modo, torna-se relevante que as cidades possuam praças, aqui consideram-se praças em sentido amplo, conotando a ideia do acesso ao lazer de maneira democrática, bem como, promotora de funções ambientais para a cidade de Guanambi - BA.

$\mathrm{Na}$ presente pesquisa foram mapeadas 30 praças contidas no espaço intraurbano de Guanambi, um total de 120.162,03 $\mathrm{m}^{2}$ (Mapa 2).

Mapa 2- Localização das praças no Espaço Urbano de Guanambi

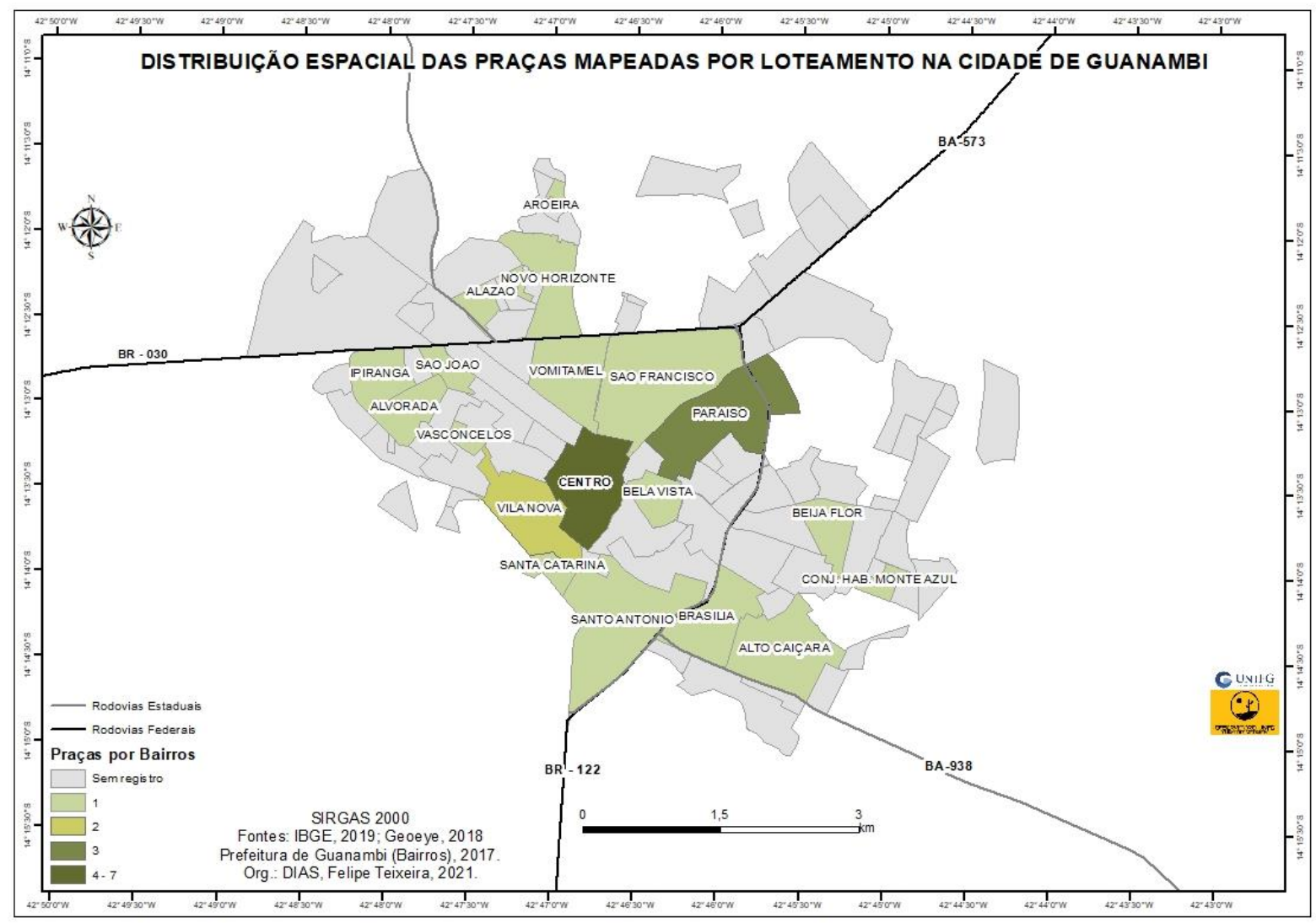

Org: Autores, 2021.

A somatória da cobertura vegetal contidas em todas as praças foi de $11.596,6 \mathrm{~m}^{2}$. Dentre as praças mapeadas, 4 delas não possuem nenhum tipo de cobertura vegetal. Observase que nenhuma delas possui mais que $26 \%$ de área de cobertura vegetal arbórea-arbustiva, apresentando significativa variabilidade na relação entre a cobertura vegetal e a área de cada praça vetorizada conforme pode ser visualizado na imagem a seguir (Mapa 3). 
Baixa qualidade ambiental de praças baseada em índices de cobertura vegetal em cidade de pequeno porte

Felipe T. Dias; Carlos Clemente; Deborah M. Pereira; Jardel G. S. Costa; Nário J. M. de Oliveira

Mapa 3 - Ocupação de áreas por praça em cada bairro

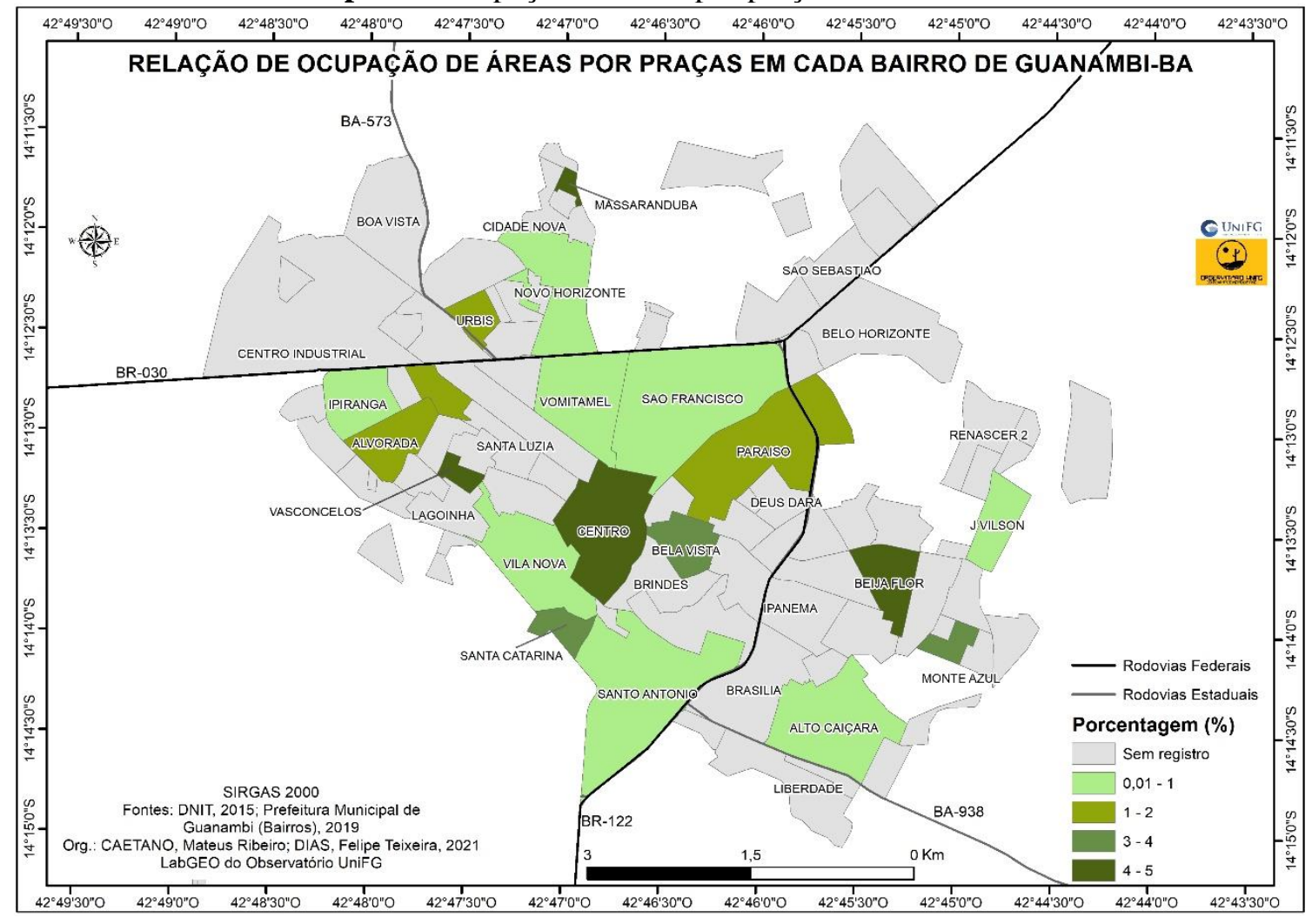

Org: Autores, 2021

Destarte necessária a discussão em torno à ocupação de áreas por praça em cada bairro da cidade, conforme mapa anterior, é necessário também uma visão ampla sobre as discussões inerentes aos indices de cobertura vegetal contida nas áreas das praças mapeadas. Nesse sentido, o mapa 4, produto de uma vetorização da cobertura vegetal, evidencia os indices por praças no espaço intraurbano de Guanambi/BA. 
Baixa qualidade ambiental de praças baseada em índices de cobertura vegetal em cidade de pequeno porte

Felipe T. Dias; Carlos Clemente; Deborah M. Pereira; Jardel G. S. Costa; Nário J. M. de Oliveira

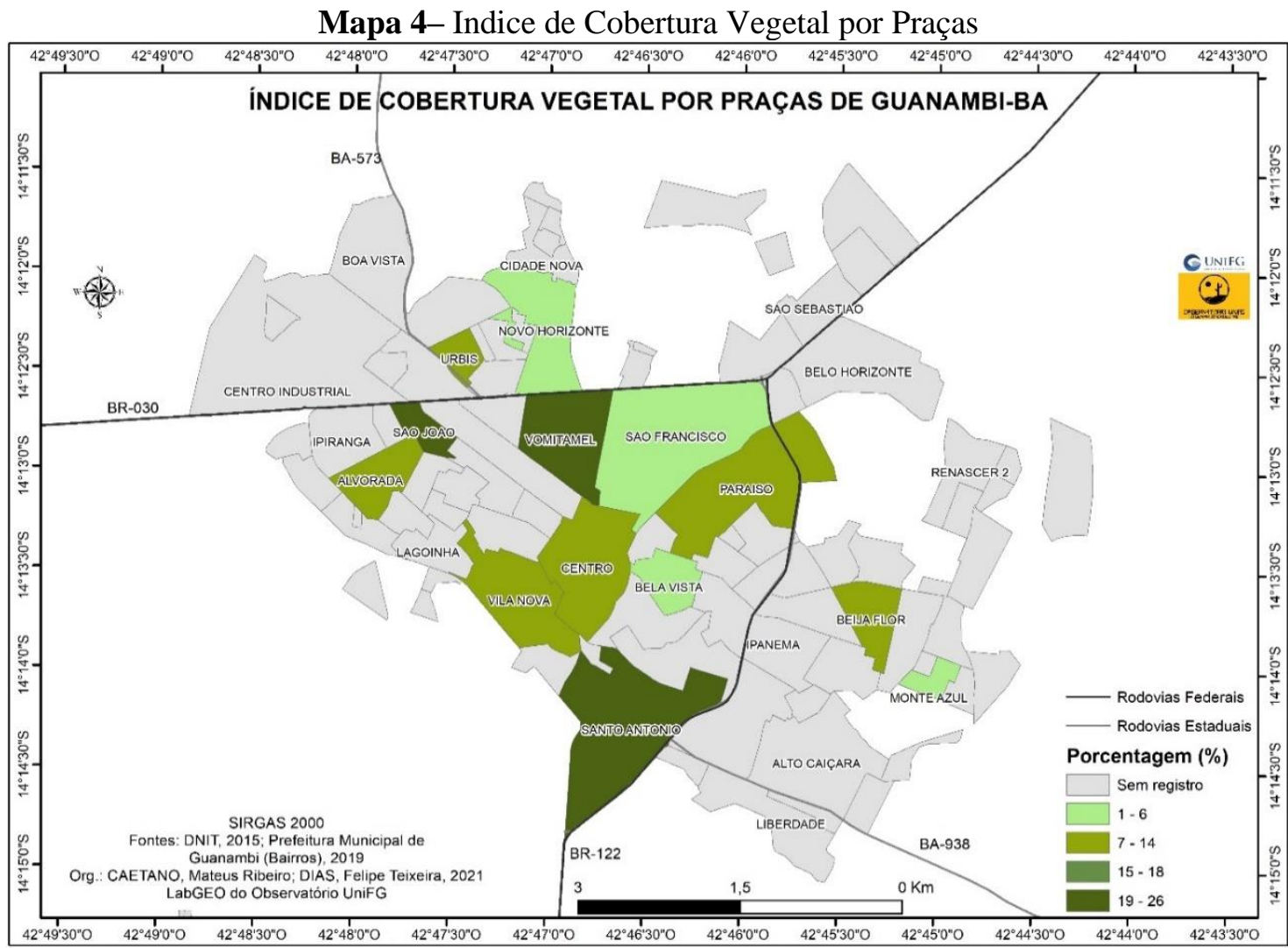

Org: Autores, 2021.

Nesse contexto, verifica-se que as praças localizadas na região central da cidade e seu entorno imediato apresentam um quantitativo de cobertura vegetal maior entre as áreas selecionadas (entre $24,3 \%$ e $26 \%$ ). Porém, aquelas situadas nas regiões mais periféricas dispõem de vegetação expressivamente menor (entre $0,21 \%$ e $7,77 \%$ ), principalmente em loteamentos recentes (Mapa 4). Esse padrão espacial foi verificado, também, por Clemente et al., (2019) na cidade de Guanambi - BA, em estudos realizados a partir da cobertura vegetal da cidade.

Não obstante, o IAVT observado na área urbana de Guanambi foi de $1,88 \mathrm{~m}^{2}$ por habitante. Neste sentido, observa-se que o valor do índice encontrado para a cidade de Guanambi está abaixo do mínimo ideal sugerido pela Organização das Nações Unidas (ONU) e Organização Mundial da Saúde (OMS), que sugerem um índice, no mínimo, de $12 \mathrm{~m}^{2}$ por habitantes (BORGES et al, 2012).

De acordo com Arruda et. al. (2013), na área central da cidade de Mossoró - RN, semiárido brasileiro, o IAVT alcançou $0,57 \mathrm{~m}^{2}$. Em Vinhedo -SP, cidade com porte semelhante a Guanambi, os pesquisadores Harder et al. (2006) encontraram um IAVT de 2,19 $\mathrm{m}^{2}$ por habitante. Ambas as cidades possuem quantitativos abaixo dos parâmetros satisfatórios. 
Baixa qualidade ambiental de praças baseada em índices de cobertura vegetal em cidade de pequeno porte

Felipe T. Dias; Carlos Clemente; Deborah M. Pereira; Jardel G. S. Costa; Nário J. M. de Oliveira

Por outro lado, Pirovani et. al (2012) encontraram em Cachoeiro do Itapemirim - ES um índice de IAVT de $35,04 \mathrm{~m}^{2} / \mathrm{hab}$, valor 18 (dezoito) vezes maior do que o percebido em Guanambi. A partir disso, constata-se que o índice de cobertura vegetal das praças encontrado na área intraurbana de Guanambi encontra-se distante dos níveis considerados ideais pelos órgãos internacionais contrastando ainda com resultados obtidos por outros estudos em cidades brasileiras.

Nessa perspectiva, dada à realidade guanambiense, considera-se um desafio ambiental frente às projeções arquitetônicas, promotoras de ideáis de um embelezamento artificial nos espaços de recreamento - meramente contruções civis- em detrimento do incentivo à cobertura vegetal em espaços de lazer, e circulação (PARADEDA, 2003).

Desse modo, o Mapa 5, produto da seleção de duas praças com um distanciamento similar da área central constitui-se como um comparativo necessário, posto que o lapso temporal das praças denominadas A e B no mapa, possuem referências distintas sendo 1980 e 2007 respectivamente (DIAS, et al., 2019). O que ratifica à ideia de uma nova arquitetura que propicia espaços de recreamentos com aparatos artificiais, em detrimento do uso do espaço com vegetação (PARADEDA, 2003).

Mapa 5- Comparativo entre praças com lapso temporal/localidades distintos

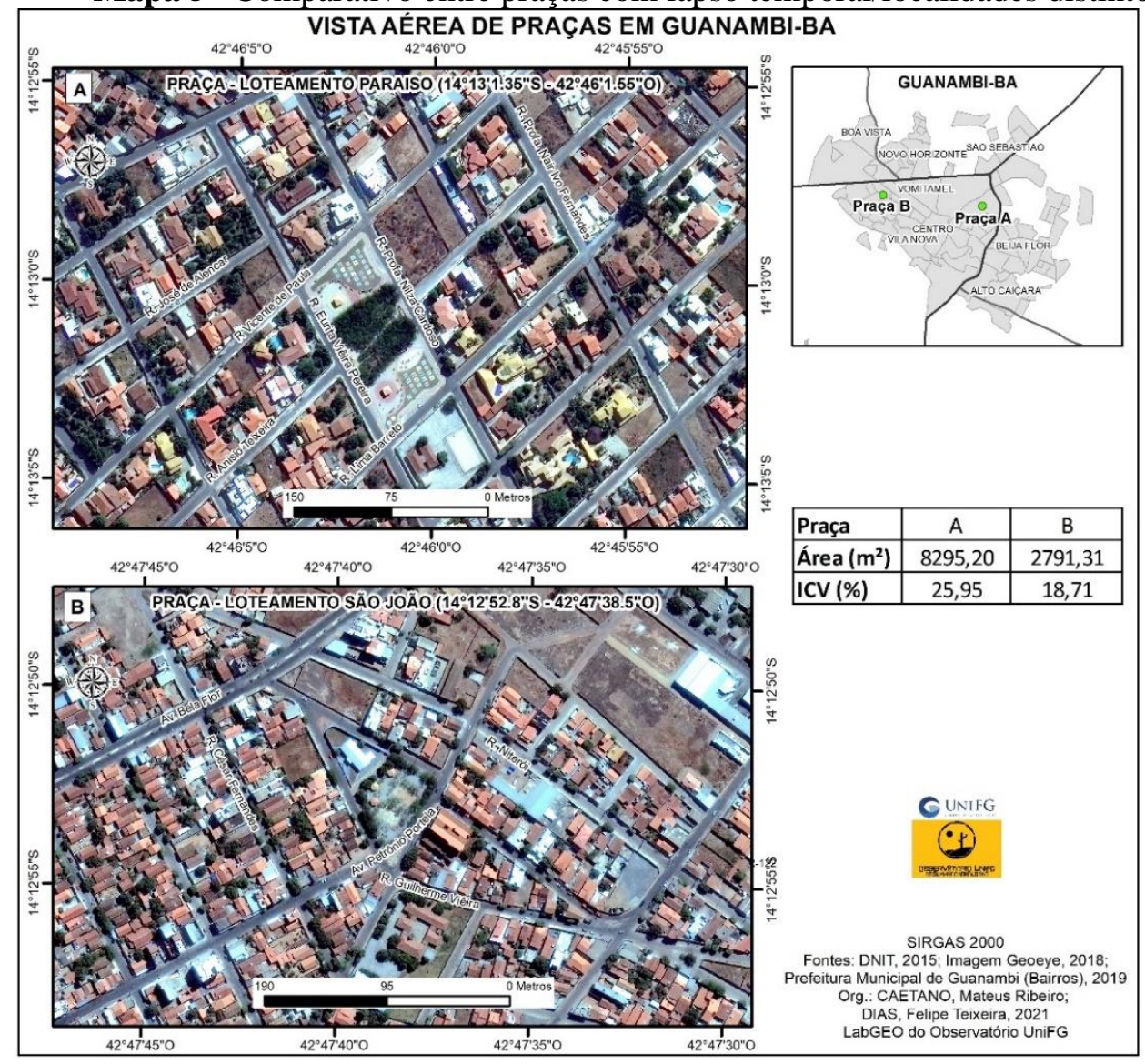

Org: Autores, 2021. 
Baixa qualidade ambiental de praças baseada em índices de cobertura vegetal em cidade de pequeno porte

Felipe T. Dias; Carlos Clemente; Deborah M. Pereira; Jardel G. S. Costa; Nário J. M. de Oliveira

Em relação ao ICV, a cidade de Guanambi apresenta o índice de 0,199 m²/hab. de copa em praças/habitantes. Em Mossoró - RN, semiárido brasileiro, o ICV encontrado por Arruda et.al. (2013) na região central foi de 9,57 $\mathrm{m}^{2}$. Em Curitiba - PR o ICV é de 3,06 $\mathrm{m}^{2} /$ hab., valor 15 (quinze) vezes maior do que o obtido em Guanambi.

Os indicadores encontrados na cidade de Guanambi - BA, se distanciam de praças promotoras de serviços ambientais, tais como, infiltração no solo, influência na amenização da temperatura média local, entre outros atributos. Na realidade de Guanambi, o aspecto ambiental promovido pela cobertura vegetal das praças é particularmente relevante em virtude da cidade estar situada a 525 metros de altitude, e de acordo com os dados da Weather Spark (2019) apresentar em geral temperatura variada entre $17{ }^{\circ} \mathrm{C}$ a $35^{\circ} \mathrm{C}$ e raramente superior a 38 ${ }^{\circ} \mathrm{C}$, tendo uma média anual de $25,6{ }^{\circ} \mathrm{C}$, sendo o calor fator predominante na maior parte do ano. Desse modo, é relevante que a cidade de Guanambi disponha de ampla cobertura vegetal em suas praças, no intuito de contribuir para o conforto térmico e propiciar maior qualidade de vida aos citadinos.

A ausência de boa qualidade nas praças, faz com que a cidade de Guanambi - BA se distancia da efetividade dos aspectos da política urbana ambiental, visto que as praças constituem um elemento urbanístico e ambiental que corroboram com os aspectos socioambientais das cidades (BRASIL, 1988). Tais funções são resguardadas de forma legal pela Constituição Federal de 1988, bem como pelo Estatuto da Cidade (Lei 10.257/2001) e outros regramentos específicos (BRASIL, 2001).

Desse modo, é importante que as cidades possuam praças que promovam o lazer, bemestar e a qualidade de vida nas cidades, dispondo assim, de cobertura vegetal que possa efetivamente contribuir para o equilíbrio ambiental, recreação, higienização do espaço, embelezamento, regulação térmica, redução de ruídos e poluentes, entre outras benesses para a população (AMORIM; LIMA, 2006).

\section{CONSIDERAÇÕES FINAIS}

A partir da análise da cobertura vegetal das praças localizadas na área urbana de Guanambi, encontrou-se o índice de 0,199 $\mathrm{m}^{2} / \mathrm{hab}$. Assim, verifica-se que o IAVT se encontra abaixo do índice recomendado pelos órgãos internacionais, diga-se ONU e OMS, os quais sugerem e $12 \mathrm{~m}^{2}$ por habitantes. O ICV também se apresenta como insatisfatório quando comparado com os resultados obtidos em outras cidades. Além disso, verificou-se uma 
Baixa qualidade ambiental de praças baseada em índices de cobertura vegetal em cidade de pequeno porte

Felipe T. Dias; Carlos Clemente; Deborah M. Pereira; Jardel G. S. Costa; Nário J. M. de Oliveira

distribuição díspar da cobertura vegetal, sobretudo verificando suas localidades em detrimento de sua inauguração.

A partir desse contexto, verifica-se que há uma preocupação técnico-científica por parte de conselhos e órgãos internacionais que buscam orientar à idealização mínima para uma cidade que possua uma cobertura vegetal satisfatória, apontando que estes índices mínimos possam contribuir para a qualidade e/ou melhoria ambiental nos espaços de lazer e recreação, oportunizando a melhora da saúde, bem-estar, embelezamento, socialização e promoção de um ambiente ecologicamente equilibrado.

Sendo assim, estudos que versem sobre as praças e cobertura vegetal nas cidades são relevantes para subsidiar e fomentar políticas públicas que visem a melhoria da qualidade de vida e do meio ambiente no espaço urbano. Recomenda-se estudos futuros que abordem sobre os tipos de vegetação que efetivamente contribuem com a preservação ou restauração de populações de insetos polinizadores.

\section{REFERÊNCIAS}

AMORIM, Margarete C. de Costa Trindade; LIMA, Valéria. A importância das áreas verdes para a qualidade ambiental das cidades. Revista Formação Online, v. 1, n. 13 (2006). Disponível em: <http://revista.fct.unesp.br/index.php/formacao/article/view/835/849>. Acesso em: 26 de abr. de 2019.

BORGES, Cézar Augusto Reis da Fonseca; MARIM, George Costa; RODRIGUES, José Edilson Cardoso. Mapeamento da cobertura vegetal do bairro Marambaia - Belém/PA. Revista REVSBAU, Piracicaba - SP, v.7, n.4, p.16- 26, 2012. Disponível em: <https://tinyurl.com/ue7d6nh>. Acesso em: 13 dez. de 2019.

BRASIL. Constituição da república federativa do Brasil de 1988. Disponível em: <http://www.planalto.gov.br/ccivil_03/constituicao/constituicao.htm> Acesso em: 01 abr. 2019.

BRASIL. Lei 10.257/2001, 10 de julho de 2001. Regulamenta os arts. 182 e 183 da Constituição Federal, estabelece diretrizes gerais da política urbana e dá outras providências. Disponível em: <http://www.planalto.gov.br/ccivil_03/leis/LEIS_2001/L10257.htm>. Acesso em: 01 abr. 2019.

BRASIL. Ministério do Meio Ambiente. Conselho Nacional de Meio Ambiente. Resolução CONAMA 358/2005. Disponível wm: <www.mma.gov.brt>. Acesso em 27 de agosto de 2019.

CARVALHO, Cláudio; RIBEIRO, Guilherme; RODRIGUES, Raoni. EM BUSCA DA CIDADE: A luta pela moradia adequada como força motriz da reforma urbana. Rio de Janeiro: Lumen Juris, 2016. 
Baixa qualidade ambiental de praças baseada em índices de cobertura vegetal em cidade de pequeno porte

Felipe T. Dias; Carlos Clemente; Deborah M. Pereira; Jardel G. S. Costa; Nário J. M. de Oliveira

CÂMARA, Gilberto; DAVIS, Clodoveu; MONTEIRO, Antônio Miguel Vieira. Introdução à Ciência da Geoinformação: Capítulo 1 - Apresentação. São José dos Campos (SP): Instituto Nacional de Pesquisas Espaciais (INPE), 2001. Disponível em: <http://www.dpi.inpe.br/gilberto/livro/ introd/>. Acesso em: 4 mai. 2019.

CLEMENTE, Carlos Magno Santos; PEREIRA, Deborah Marques; MAGALHÃES, Hellen Pereira Cotrim; ARAÚJO, Caroline Gonçalves. COBERTURA VEGETAL E QUALIDADE DE VIDA: CIDADE DE GUANAMBI, SEMIÁRIDO BAIANO. Caminhos de Geografia, v. 20, n. 72, p. 136-148, 2019.

DIAS, Felipe Teixeira, OLIVEIRA, Nário Martins, PEREIRA, Deborah Marques, CLEMENTE, Carlos Magno Santos. POLÍTICA URBANA E DIREITO À CIDADE: ANÁLISE DAEXPANSÃO DA MANCHA URBANA DE GUANAMBI NOS ANOS DE 1987 A 2017. IN. V Semana Jurídica da UniFG: O Legado dos 30 Anos da Constituição Brasileira: Democracia, Sociedade e Novos Direitos. 2019. Disponível em: <http://www.semanajuridicaunifg.com.br>; acesso em: 20 Ago. 2020.

FONSECA, M. F. Geotecnologias aplicadas ao diagnostico do uso da terra no entorno do Reservatório de Salto Grande, município de Americana (SP), como subsídio ao planejamento territorial. 82 f. Dissertação (Mestrado em Ciências) - Universidade Estadual de Campinas, Campinas (SP), 2008.

HARDER, Isabel Cristina Fialho; RIBEIRO, Roberval de Cássia Salvador; TAVARES, Armando Reis. Índices de Área Verde e Cobertura Vegetal para as praças do município de Vinhedo - SP. Revista Árvore, Viçosa-MG, v.30, n.2, p.277-282, 2006. Disponível em: https://tinyurl.com/v5b5zeq. Acesso em: 14 nov. de 2019.

IBGE. IBGE Cidades. Guanambi. Disponível em: 〈https://cidades.ibge.gov.br/>. Acesso em: 10 mar. 2020.

LAMAS, J. M. R. G. Morfologia urbana e desenho da cidade. Lisboa: Fundação Calouste Gulbenkian/Junta Nacional de Investigação Científica e Tecnológica, 1993.

LEFEBVRE, Henri. O Direito à Cidade. São Paulo: Ed. Nebli. 2016.

LEITE, MARCOS ESDRAS. Geotecnologias aplicadas ao mapeamento do uso do solo urbano e da dinâmica de favela em cidade média: o caso de Montes Claros/MG. Tese (Doutorado em Geografia) - Instituto de Geografia, Universidade Federal de Uberlândia, p.288, 2011.

MACEDO, S. S.; ROBBA, F. Praças brasileiras. São Paulo: Edusp, 2002.

MATIAS, Lindon Fonseca. Por uma economia política das geotecnologias. Scripta Nova. Revista Electrónica de Geografia y Ciencias Sociales. VII(170) (52), 2004. Disponível em: http://www.ub.es/geocrit/sn/sn-170-52.htm. Acesso em: 5, Mai., 2019.

MENDONÇA, Eneida Maria Souza. Apropriações do espaço público: alguns conceitos. Estudos e Pesquisas em Psicologia, UERJ, RJ, v. 7, n. 2, p. 296-306, ago. 2007. Disponível em: https://tinyurl.com/uzf3bna. Acesso em: 14 nov. de 2019. 
Baixa qualidade ambiental de praças baseada em índices de cobertura vegetal em cidade de pequeno porte

Felipe T. Dias; Carlos Clemente; Deborah M. Pereira; Jardel G. S. Costa; Nário J. M. de Oliveira

NUCCI, J. C. Qualidade ambiental e adensamento urbano: um estudo de ecologia e planejamento da paisagem aplicado ao distrito de Santa Cecília (MPS). $2^{\circ}$ ed. - Curitiba, 2008.

OLIVEIRA JUNIOR, Israel de; PEREIRA, Anderson de Jesus. Índice de vegetação e degradação ambiental: uma abordagem multitemporal no polo regional de GuanambiBA. Revista de Geociências do Nordeste, v. 2, p. 875-884, 27 out. 2016. Disponível em: periodicos.ufrn.br/revistadoregne/article/view/10547. Acesso em: 13 out. de 2020.

PARADEDA, Maria Regina Matos. Arquitetura da paisagem e modernidade: um estudo sobre representações e memória das praças de Pelotas: 1860-1930. 2003. Dissertação de Mestrado. Pontifícia Universidade Católica do Rio Grande do Sul.

PIROVANI, Daiani Bernardo; SILVA, Aderbal Gomes da; OLIVEIRA, Onair Mendes de; CALIMAN, Jônio Pizzol. Áreas Verdes Urbanas de Cachoeiro de Itapemirim-ES. Enciclopédia BIOSFERA, Centro Científico Conhecer, Goiânia, v.8, n.15; p. 171, 2012. Disponível em: https://tinyurl.com/wadjogs. Acesso em: 06 fev. de 2020.

RIGOTTI, G. Urbanistica - la tecnica. 2. ed. Torino: Editrice Torinese, 1956.

ROSA, R. Geotecnologias na Geografia aplicada. Revista do Departamento de Geografia, p. 81-90. 2005.

SANTOS, Milton. A Natureza do Espaço técnica e tempo razão e emoção. São Paulo: Hucitec 2 2a edição, 1997.

VALDIVINO, L. F. X.; MATOS, L. S.; OLIVEIRA, F. L. S. Geotecnologias aplicada ao planejamento urbano: um estudo de caso sobre a acessibilidade na comunidade Alto Bela Vista, Pacoti - Ceará. Revista de Geociências do Nordeste, p. 1151-1159. 2016.

VIERO, Verônica Crestani; BARBOSA FILHO, Luis Carlos (2009). Praças Públicas: origem, conceitos e funções (PDF). Jornada de Pesquisa e Extensão, ULBRA Santa Maria. Consultado em 24 de janeiro de 2016

WEATHER SPARK. ORG. Guanambi. Dados climáticos para cidades mundiais. Disponível em: <https://pt.weatherspark.com/y/30715/Clima-característico-em-GuanambiBrasil-durante-o-ano>. Acesso em: 23 mai. 2020.

Artigo recebido em: 20 fevereiro de 2021

Artigo aceito em: 05 de março de 2021.

Artigo publicado em: 12 de março de 2021. 